\title{
DIVERSIFICATION GAINS FOR A HOME BIASED TRADER IN THE EMERGING AND FRONTIER EQUITY MARKETS
}

\author{
Seema Wati Narayan*, Sivagowry Srianathakumar**, Greeni Maheshwari***, and \\ Mobeen Ur Rehman**** \\ * Corresponding author. Independent Researcher, Melbourne, Australia. Email: swdhar27@gmail.com \\ ** Independent Researcher, Melbourne, Australia \\ *** School of Business and Management, Economics and Finance, RMIT University, \\ Ho Chi Minh City, Vietnam \\ **** South Ural State University, 76 Lenin prospekt, Chelyabinsk, Russian Federation.
}

\begin{abstract}
We study the case of a home-biased equity trader based in Asia, Central and Eastern Europe, the Middle East and North Africa, or Latin America, who is looking at diversifying his/her investment risks internationally within his/her region and three other emerging/frontier regions. We focus on explaining the dynamic conditional correlations between equity markets from 3 January 2002 to 11 November 2016. Timevarying opportunities for diversification are found in several nations across regions. However, diversification opportunities outside a region are largely reserved for bad times, such as during the global financial crisis and the European sovereign debt crisis.
\end{abstract}

Keywords: DCC-GARCH; Emerging and frontier markets; Financial crisis; European Sovereign debt crisis.

JEL Classifications: G11; G15.

\section{Article history:}

Received : July 07, 2021

Revised : : August 07, 2021

Accepted : September 24, 2021

Available online : September 30, 2021

https://doi.org/10.21098/bemp.v24i3.1702 


\section{INTRODUCTION}

Modern portfolio theory posits that higher diversification gains can be achieved if the investment portfolio is made up of weakly (and/or negatively) correlated assets. Combining assets that have negative or low correlations with each other within a portfolio provides superior risk-adjusted returns (Markowitz, 1952). This theory has generated significant research that has sought to explain the correlations between markets. Early studies focused on developed markets as these were the most active markets for investors and traders. ${ }^{1}$ Since financial liberalisation has occurred in emerging nations, their stock markets have also become lucrative for portfolio diversification among traders and investors in developed nations. Not surprisingly, therefore, since the 2000s, many studies have examined the comovement between developed and emerging markets. But only recently have academics begun to examine diversification opportunities between emerging stock markets (see survey of this strand of literature in Section II).

Our paper contributes to the group of studies that examines pairwise dynamic conditional correlations between emerging markets and across regions, focusing on Asia, Central and Eastern Europe (CEE), Middle East and North Africa (MENA), and Latin America. We employ one of the more commonly used Dynamic Conditional Correlations (DCC) GARCH models, closely following the work of Engle (2002), to estimate the dynamic correlations between stock markets, which we then used to measure portfolio diversification opportunities over the period from 3 January 2002 to 11 November 2016. While the DCC method has been used to evaluate portfolio diversification opportunities, this research differs from other studies in three important ways.

First, we include emerging markets from four global regions, namely Asia, CEE, Latin America, and MENA. A key feature of the current body of research is that it is primarily focused on diversification within a region, making it rather regionally biased. Indeed, previous studies have reported that investors are regionally biased given the extent of capital controls, limited access to the market, and information on markets in other regions (Baltzer et al., 2013; de Dreu and Bikker, 2012). Baltzer et al. (2013) examine the nature of cross-border stockholding among individual German investors and find that German investors living close to foreign nations are inclined to be less biased towards foreign investment. When examining the 1999-2006 investment policies of 857 Dutch pension funds, de Dreu and Bikker (2012) find that many pension funds favour regional investment. This literature is rooted in studies that have shown strong evidence of home bias in investment in equity markets among both institutional and individual investors (French and Poterba, 1991; Cooper and Kaplanis, 1994; Tesar and Werner, 1995).

Similarly, Coval and Moskowitz (2001) identify local bias among US fund managers, who invest heavily in the same city and receive substantial abnormal

\footnotetext{
For example, Grubel (1968) and Solnik (1974) were among the first to document national stock markets diversification attributable to the financial liberalisation of emerging economies. Similarly, Lessard (1973), Agmon and Lessard (1977), and Errunza (1977; 1983) examined emerging markets in general to investigate portfolio diversification opportunities for international investors. Other significant work in the early 1970 's on portfolio diversification attributable to financial liberalisation in emerging markets include Grubel and Fadner (1971), Ripley (1973), Makridakis and Wheelwright (1974), Panton et al. (1976), Maldonado and Saunders (1981), and Philippatos et al. (1983).
} 
returns in local investment, which is attributed to local information advantage (also see Ivković and Weisbenner, 2005). Several other reasons for home bias have been documented, including restrictions on international capital flows (Stulz, 1981; Serrat, 1997), a lack of international exposure (Kang and Stulz, 1997), familiarity with language and culture (Grinblatt and Keloharju, 2002), and distance (Grinblatt and Keloharju, 2002). However, considering the internet revolution and financial liberalisation, these barriers are dissipating. Since more and more traders/investors are looking to diversify their portfolio internationally, this study will prove to be useful in explaining the correlations or opportunities for diversification within the four regions. By looking at the past performances, the study indicates the choices available to investors, in emerging or frontier countries, who have a locally based portfolio, but wish to diversify their portfolio internationally. Since the study uses daily data at the national stock market level, the results guide traders about DCCs between the domestic market against others. ${ }^{2}$

Second, we estimate the daily DCCs between market pairs across all four regions. ${ }^{3}$ We explore opportunities for diversification for short-term (daily) traders. We find that the extant literature includes only one study for Asia (see Qian and Diaz (2017), who use data for the period 1999-2015) and one on Latin America (for Latin America, see Hwang (2014), who use data for the period 2006-2010). Almost all studies on the MENA region use daily data (see El Hedi Arouri and Nguyen (2010), for the period 2005-2008; and Bouri (2014), for the period 2005-2013). All DCC based studies on CEE use daily data (see Wang and Moore (2008), for the period 1994-2006; Šikić and Šagovac (2017), for the period 1997-2016; Pietrzak et al. (2017), for the period 1997-2015; Dajčman and Festić (2012), for the period 19972010; and Harkmann (2014), for the period 2002-2012). While some studies examine the daily behaviour of traders, these studies are different from ours in that they only consider regionally biased investments for one or two nations in any of the four regions. Our study comprehensively captures the short-term (daily) trader international portfolio investment behaviour within an emerging region and other emerging regions. Our study captures stock markets over the 2000-2016 period, which is an important timeline that captures the Global Financial Crisis (GFC), and the European Sovereign Debt Crisis (ESDC).

Third, consistent with the literature, we examine the DCCs over different samples of data: the full period (3 January 2002 - 11 November 2016), the GFC (2007-2009), and the ESDC (2009-2013), and the periods preceding and following these events. The tests related to the ESDC are designed to capture the behaviour of DCCs in CEE nations, which were most affected by the ESDC. What sets us apart is the fact that we focused on short term effects of the crises on traders.

Foreshadowing some of our key findings, we show that while there are some well-connected Asian markets (such as India and Indonesia) with reduced opportunities to diversify risks in recent years, several other Asian nations show no or a low level of integration with other emerging/frontier markets and hence

2 The study does not include developed markets. Since we examine pairwise DCCs, our findings will not change with the inclusion of developed markets. We found that there is significant research in this area (see Narayan et al., 2014; Narayan et al., 2018).

3 Our study reports pairs for which time-varying correlations are not rejected. All time-varying DCCs are available in Figure S1. 
investors could benefit significantly from diversifying their risks in other emerging/ frontier markets within the four regions examined here. For CEE nations, there is more opportunity to diversify risks outside CEE than within CEE markets. The DCCs between the CEE markets, except for Greece, rose in the ESDC period, which is a sign of contagion. In the case of the MENA markets, there were no connections with Latin American markets and only weak connections with the markets in the other two regions. However, South Africa's stock market was an exception - it was found to be strongly integrated with Asian markets. The Latin American markets were found to have significant short-term connections with the MENA markets but very low connections with other markets both within Latin America and CEE nations, making emerging and frontier markets lucrative for short-term diversification.

The remainder of the paper is organised as follows. Section II provides a review of the literature that has examined correlations using the DCC-GARCH methodology across the four regions. Section III briefly explains the models used in this study, while Section IV presents the data. Section V reports and discusses the DCC results and highlights our findings by region and by country for the full sample, and sub-samples covering the financial crises. Here, we also present regression analyses that formally test the relationship between DCCs between the markets and financial crises. The final section provides some concluding remarks.

\section{LITERATURE REVIEW}

This section reviews studies that utilise the DCC approach to examine stock market integration in the four regions of interest to the present study: MENA, CEE, Asia, and Latin America.

\section{A.1. Asia}

Sriananthakumar and Narayan (2015), Lean and Teng (2013), Narayan et al. (2014), Qian and Diaz (2017), and Budd (2018) are among those who have study stock market integration in the Asian region using the DCC family of models. Sriananthakumar and Narayan (2015) investigate short-term stock market integration with monthly indices for the period 1993 to 2013 between Sri Lanka and selected economies, including India, China, Malaysia, Pakistan, Singapore, and the United States (US). Their findings reveal that Sri Lanka had low correlations with all these nations other than China, for which the correlation was the largest.

Lean and Teng (2013) examine the integration of the Malaysian stock market with two leading world economies (the US and Japan) and two powerful emerging economies (China and India) using the DCC-GARCH approach based on monthly indices from 1991 to 2010 and identified that Malaysia was weakly correlated with China and Japan but highly correlated with India and the US. The correlations found between Malaysia and India and between Malaysia and the US were similar in magnitude.

Narayan et al. (2014) compare market integration between Asian nations and the US, Australia, and two emerging Asian markets, China, and India, on a daily, weekly, and monthly basis of stock prices from 2001 to 2012 for the pre- 
GFC period, during the GFC, and the post-GFC period, using the DCC-GARCH approach. They also investigated the causes of identified time-varying bilateral correlations. They find that the monthly integration was the strongest compared to the weekly and daily correlations. For the Asia-India correlation, the market characteristics and the GFC were found to exert a strong influence, while the Asia-China correlation was not influenced by any of the factors considered for the monthly correlation. When the full sample was considered using the monthly, weekly, and daily values, the highest correlation was found between Asia and China, while the lowest correlation was found between Asia and the US.

Qian and Diaz (2017) use daily data from 1999 to 2015 for a group of 14 developed and developing countries from five continents-America, Europe, Asia, Africa, and Oceania - to determine their short- and long-run correlations with Malaysia's stock market using Baba, Engle, Kraft, and Kroner (BEKK), multivariate GARCH (MGARCH), CC-MGARCH, and DCC-GARCH methods. These authors find that, in the long term, every market paired with Malaysia showed a moderate level of integration, and that any instability in Malaysian market may be due to other factors, such as political or social conflict. Budd (2018) model the integration effects of four Asia-Pacific countries with the US stock market using a DCC-Exponential GARCH (EGARCH) model and found that there was a high degree of correlation between these markets during crisis periods. Joyo and Lefen (2019) examine the DCC-GARCH models of developed (US and UK) and emerging (Pakistan, China, Indonesia, and Malaysia) markets from 2005 to 2018 and show close integration between Pakistan's stock market and other markets during the GFC. The authors note that the integration decreased after the GFC period.

Hung (2019) investigates the short-term dynamic correlations between China and four Southeast Asian countries (Vietnam, Thailand, Singapore, and Malaysia) during period 2008-2018 using the MGARCH-ADCC method and the Chines stock market to be relatively integrated with other Asian markets after the GFC.

\section{A.2. MENA}

Several previous studies explore stock market integration in MENA using the DCC-GARCH approach, including those by Maghyereh et al. (2015), Arouri and Nguyen (2010), and Bouri (2014). Maghyereh et al. (2015) consider the daily stock prices of the markets in the US and a group of MENA countries for the years 2005-2013 to investigate stock market integration before and after the GFC. Their results suggest weak integration between the MENA countries and the US prior to the crisis but that these integrations were strong after the crisis.

Arouri and Nguyen (2010) focus on stock market integration between the world markets (based on the Morgan Stanley Capital International [MSCI] indices) and the markets of a few select countries (Kuwait, Oman, Qatar, the United Arab Emirates (UAE), and Saudi Arabia). Using daily data from June 2005 to June 2008, they find a weak correlation between these countries and the world markets, and a moderate correlation between the national pair-wise markets of Oman and Qatar, Qatar and the UAE, and the UAE and Saudi Arabia, suggesting a substantial investment opportunity for global investors to improve their returns by investing in these markets. Bouri (2014) investigates the correlation of 12 equity 
markets in the MENA region by collecting daily data from 2003 to 2015 to identify the opportunities for regional diversification, and the results indicated that the highest correlation occurred between Qatar and the UAE (0.392), while the lowest correlation was found between Morocco and Lebanon (0.017). However, Bouri's (2014) study overlooked important diagnostics testing such as ARCH Lagrange Multiplier test on the stock price indices to test for the presence of heteroscedasticity in the models used in the study.

\section{A.3. CEE}

Research carried out by Šikić and Šagovac (2017), Pietrak et al. (2012), Dajcman and Festic (2012), Harkmann (2014), and Wang and Moore (2008) focus on CEE market integration regionally and globally. All these authors use the DCCGARCH approach, except Wang and Moore (2008), who utilise the DCC-EGARCH approach to identify the stock market integration with various regions.

Šikić and Šagovac (2017) investigate stock market integration between the Croatian and several other markets (the US, the UK, Germany, Poland, Austria, the Czech Republic, and Hungary) during regional crises and the GFC, using daily stock prices from September 1997 to August 2016. These authors find that during the Russian Crisis, there was a low level of integration between the Croatian market and other markets, globally and regionally, while there was no effect of the dot-com and 9/11 shocks on the Croatian international financial integration. Pietrak et al. (2012) focus on the long-term integration of the German market with the markets of four CEE countries (Austria, the Czech Republic, Hungary, and Poland) by using daily data for the period 1997-2015. Their study finds that the German market had a significant impact across the whole region during this time.

Dajcman and Festic (2012) determine the interdependence between the Slovenian and six European markets using daily stock market returns from April 1997 to May 2010. They find that there was increased integration between Slovenia and these European markets during the GFC period, but a similar effect was not seen within the CEE stock markets. However, one must be cautious about their findings because they did not cover a wide range of CEE countries. In a similar vein, Harkmann's (2014) study focuses on stock market integration between CEE countries and Western Europe and show that the integration between these countries substantially increased during the GFC, in line with the findings of other studies on the CEE region. However, this study did not carry out any diagnostics testing.

Wang and Moore (2008) consider the integration between three emerging CEE markets (the Czech Republic, Hungary, and Poland) during the pre-GFC period using daily data from 1994 to 2006. They also investigate the causes of the identified correlations and find that increasing stock market integration within these countries was not due to any macro-economic or monetary convergence but rather due to developments in the financial sector. 


\section{A.4. Latin America}

Panda and Nanda (2018), Hwang (2014), and Lahrech and Sylwester (2011) investigate stock market integration in the Latin American region using the same DCC-GARCH approach and drawing on weekly data from 1995 to 2015 and find that co-movements were higher towards the end of the sample period than in the early phase. Within this region, there was strong stock market integration between Argentina, Brazil, Chile, and Peru, followed by Colombia, whereas Venezuela was least correlated with the group.

Hwang (2014) investigates the stock market integration of four Latin American stock markets (Argentina, Brazil, Chile, and Mexico) before, during, and after the GFC period, using daily data from January 2006 to December 2010. He finds that the markets in Argentina, Brazil, and Mexico were heavily affected by the financial crisis, while this effect on the Chilean stock market was lower.

Using weekly stock market data from December 1998 to March 2004, Lahrech and Sylwester (2011) identify that the correlations between the US and various Latin American stock markets (Argentina, Brazil, Chile, and Mexico) strengthened with time. These results are in line with those of Hwang (2014), which indicated that the correlation between Latin American countries and the US has increased over time, except in the case of Chile. However, Lahrech and Sylwester (2011) only include a few Latin American countries, so their findings cannot be generalized to the whole Latin American region.

\section{A.4.1. Interregional Investment Opportunities}

As noted above, interregional study of DCC-GARCH models for emerging/frontier markets are still rare. In recent times, studies like Lee and Jeong (2014) examine the Northeast Asian markets and CEE markets over the period January 2000 to December 2012 using DCC-MGARCH model and find that integration between the European and Northeast Asian markets had an increasing trend, although the level of integration was not economically significant.

Similarly, Muharam et al. (2019) examine 11 markets: five Asian markets (China, Indonesia, Malaysia, Pakistan, and the Philippines), five CEE markets (the Czech Republic, Poland, Romania, Russia, and Ukraine), and the world market, using the DCC-GARCH method from May 2002 to March 2018. While they do not investigate interregional dynamic correlations, they find that China (Russia) has a lower degree of integration with the remaining four Asian CEE markets.

Besides, Robiyanto (2018) examines the DCCs between the Jakarta Composite Index (JCI) and selected emerging (and developed) market indices from January 1999 to September 2015. Using DCC-GARCH models, the study finds that the degree of integration had increased between Jakarta stock market and all other markets, except Australia, the Philippines, and Tokyo, during the GFC to postGFC period compared to the pre-GFC period.

\section{A.4.2. Emerging and Frontier Markets Versus Developed Markets}

While we do not cover the developed markets in the study, for the purpose of comparison, selected studies that examine the dynamic correlations between 
the developed markets and emerging/frontier markets are reviewed. Chittedi (2015) finds that the DCC between India and USA was higher during the postcrises periods. Similarly, Rahim and Masih (2016), who focused on the portfolio diversification benefits of Malaysian investors with major trading partners, namely China, Singapore, Thailand, Japan, and the US, found that stock markets had higher correlation after the crisis period, resulting in lesser diversification benefits. Najeeb et al. (2015) show that the diversification opportunity between the Malaysian market and other emerging and developed markets varied. Specifically, the authors suggested that the investors may not enjoy the diversification benefits if they invest in emerging markets and Asia-Pacific markets, while developed and European markets may offer effective diversification opportunities only for a short holding period of two to 64 days. In comparison, the MENA markets might bring diversification opportunities for a longer holding period of up to 256 days. Recently, Seth and Nanda (2020) examine the relationship between the Asian stock markets (India, China, Indonesia, Korea, Malaysia, and Taiwan) and the US stock market post-crisis period and find evidence of higher investment opportunities for the Indian investors in the Malaysian, Chinese and Japanese stock markets as compared to the Hong Kong, Indonesian, and South Korean stock markets. The correlation is more stable for the Indian market pairs with the US, China, and Japan markets.

\section{EMPIRICAL ANALYSIS}

The analysis of this study relies on the popular DCC model of Engle (2002).

Consider a multivariate stock return series of observations $y_{t^{\prime}} t=1,2, \ldots, T$, with $k=1,2, \ldots, K$ elements each, so that $y_{t}=\left(y_{1,}, \ldots, y_{k t}\right)^{\prime} . y_{t}$ is assumed to follow the AutoRegressive Moving Average (ARMA) process:

$$
y_{k, t}=\alpha_{k}+\sum_{n=1}^{N} b_{k, n} y_{k, t-n}+\varepsilon_{k, t}+\sum_{m=1}^{M} c_{k, m} \varepsilon_{k, t-m}
$$

where $\varepsilon_{k t}$ is the disturbance term and $m$ and $n$ are the lag lengths for the moving average and the autoregressive processes, respectively. Both the Akaike Information Criterion and Schwarz Criterion are relied on to identify the appropriate number of lag terms, $m$ and $n$, included in the conditional mean equation. by:

Assume the conditional variance of $\varepsilon_{t}$ follows the time-varying structure given

$$
\operatorname{Var}\left(\varepsilon_{t} / \Phi_{t-1}\right)=\Omega_{t}
$$

where $\varepsilon_{t}$ is the error term from the ARMA process (1) and $\Phi_{t}$ is the information set at time $t$. The variance elements of $\Omega_{t}$ are denoted by $\sigma_{k t}$ for $k=1, \ldots, K$, and the covariance elements by $\sigma_{k j t^{\prime}}$ where $1 \leq k<\mathrm{j} \leq K$. 
Let $D_{t}$ be a $K \times K$ diagonal matrix, with the $k$ th diagonal element being $\sigma_{k t}$ and let $\varepsilon_{t}=D_{t}^{-1} y_{t^{\prime}}$ where $\varepsilon_{t}$ is the standardized residual from (1) and is assumed to be serially independently distributed, with mean zero and variance matrix $\Gamma_{t}=\left\{\rho_{k j t}\right\}$. Note that $\Gamma_{t}$ is also the correlation matrix of $\varepsilon_{t}$ and

$$
\Omega_{t}=D_{t} \Gamma_{t} D_{t}
$$

Let each conditional variance of $\varepsilon_{t}$ follow a univariate $\operatorname{GARCH}(h, l)$ model given by:

$$
\sigma_{k, t}^{2}=\omega_{k}+\sum_{h=1}^{H} \alpha_{k, h} \sigma_{k, t-h}^{2}+\sum_{l=1}^{L} \beta_{k, l} \varepsilon_{k, t-l}^{2}
$$

where $\omega_{k^{\prime}} \alpha_{k, h}$ and $\beta_{k, l}$ are nonnegative and $\sum_{h=1}^{H} \alpha_{k, h}+\sum_{l=1}^{L} \beta_{k, l}<1$ for $k=1,2, \ldots, K$. For parameter parsimony $(h, l)$ is usually taken to be of low order, commonly $(1,1)$. Engle's model is defined, as in (3), with:

$$
\Gamma_{t}=\operatorname{diag}\left(q_{11, t}^{-1 / 2}, \ldots, q_{N N, t}^{-1 / 2}\right) Q_{t} \operatorname{diag}\left(q_{11, t}^{-1 / 2}, \ldots, q_{N N, t}^{-1 / 2}\right)
$$

where the $N \times N$ symmetric positive definite matrix $Q_{t}=\left(q_{i j, t}\right)$ is given by:

$$
Q_{t}=(1-\phi-\gamma) \bar{Q}+\phi \varepsilon_{t-1} \varepsilon_{t-1}^{\prime}+\gamma Q_{t-1},
$$

with $\bar{Q}$ being an $N \times N$ unconditional variance matrix of $\varepsilon_{t}$ and $\varphi$ and $\gamma$ being nonnegative scalar parameters satisfying $\varphi+\gamma<1$. Assuming normality, $\varepsilon_{t} / \Phi_{t-1} \sim$ $\mathrm{N}\left(0, D_{t} \Gamma_{t} D_{t}\right)$, the conditional log-likelihood $l_{t}$ of $y_{t}$ can be written as:

$$
l_{t}=-\frac{1}{2} \ln \left|\Gamma_{t}\right|-\frac{1}{2} \sum_{k=1}^{K} \ln \sigma_{k, t}^{2}-\frac{1}{2} \varepsilon_{t}^{\prime} D_{t}^{-1} \Gamma_{t}^{-1} D_{t}^{-1} \varepsilon_{t}
$$

from which the log-likelihood function can be written as $l^{*}=\sum_{t=1}^{T} l_{t}$. All model parameters can be estimated by maximizing $l^{*}$ with respect to unknown parameters. $^{4}$

A two-step estimation is adopted in the Engle method. The first step requires estimation of the variances via a univariate ARMA-GARCH specification, and the second step requires estimation of the parameters that capture the dynamic nature of the correlations. That is, after the univariate ARMA-GARCH models were fitted, in the second step of the DCC model, standardized residuals are used to estimate the dynamic correlations.

4 The Bollerslev and Wooldridge's (1992) quasi-maximum likelihood method is used in estimation of the model. This method generates consistent standard errors that are robust to non-normality. 


\section{DATA AND PRELIMINARY ANALYSIS}

This study employs daily MSCI-based stock market indices of the emerging markets of Asia, CEE, MENA, and Latin America over the period 3 January 2002 to 11 November 2016. The sample period sufficiently covers the financial and debt crises, GFC and ESDC.

The common statistics on the return of the MSCI-based price index for each nation, by region, are displayed in Table 1 . The mean of the MSCI returns is strongest, on average, for the Latin American region, followed by Asia, CEE, and MENA. Within the Latin American region, Venezuela shows the strongest return; for the Asian region, Bangladesh has the highest average return; for MENA, the highest average returns are seen in Egypt; and for the CEE, the highest average returns are found in Romania. The standard deviation of the returns falls in the range of 0.01-0.06 for Latin America; and 0.01-0.02 for Asia, MENA, and CEE. Negative skewness is found for most return series. The kurtosis coefficient is higher than 3 for all return series.

Table 1.

Common Statistics on Returns of Emerging Markets

This table contains selected descriptive statistics on returns for the period January 2002 to November 2016.

\begin{tabular}{|c|c|c|c|c|}
\hline Countries & Mean & Std. Deviation & Skewness & Kurtosis \\
\hline \multicolumn{5}{|c|}{ Latin America } \\
\hline Argentina & 0.0015 & 0.0222 & -0.2225 & 4.1885 \\
\hline Brazil & 0.0008 & 0.0185 & -0.1264 & 4.2236 \\
\hline Chile & 0.0009 & 0.0106 & -0.0058 & 9.5015 \\
\hline Colombia & 0.0016 & 0.0133 & -0.0959 & 20.8092 \\
\hline Mexico & 0.0015 & 0.0122 & 0.0536 & 6.0103 \\
\hline Venezuela & 0.0018 & 0.0655 & -12.7145 & 694.8166 \\
\hline \multicolumn{5}{|l|}{ Asia } \\
\hline Pakistan & 0.0017 & 0.0134 & -0.3982 & 3.4079 \\
\hline India & 0.0004 & 0.0151 & -0.1963 & 7.5908 \\
\hline Bangladesh & 0.0025 & 0.0132 & 1.2501 & 12.5435 \\
\hline China & 0.0001 & 0.0165 & -0.3102 & 4.8244 \\
\hline Sri Lanka & 0.0012 & 0.0116 & -0.5085 & 19.8101 \\
\hline Indonesia & 0.0003 & 0.0143 & -0.6344 & 5.8832 \\
\hline Korea & 0.0006 & 0.0152 & -0.6375 & 6.5825 \\
\hline Malaysia & 0.0005 & 0.0135 & -0.1012 & 5.3264 \\
\hline Philippines & 0.0004 & 0.0134 & -0.4003 & 6.1381 \\
\hline Thailand & 0.0008 & 0.0131 & -0.7316 & 10.1932 \\
\hline \multicolumn{5}{|l|}{ MENA } \\
\hline Egypt & 0.0004 & 0.0165 & -1.5081 & 25.2999 \\
\hline Greece & -0.0005 & 0.0187 & -0.3330 & 6.8613 \\
\hline Jordan & 0.0002 & 0.0108 & -0.3577 & 60.2479 \\
\hline Kuwait & 0.0002 & 0.0115 & 2.6694 & 152.4685 \\
\hline Lebanon & 0.0001 & 0.0125 & -0.9094 & 189.4453 \\
\hline Oman & 0.0002 & 0.0098 & -0.5518 & 22.7195 \\
\hline Kenya & 0.0001 & 0.0137 & -0.2170 & 732.5383 \\
\hline
\end{tabular}


Table 1.

Common Statistics on Returns of Emerging Markets (Continued)

\begin{tabular}{lcccc}
\hline Countries & Mean & Std. Deviation & Skewness & Kurtosis \\
\hline Morocco & 0.0003 & 0.0075 & -0.5615 & 7.7322 \\
Tunisia & 0.0003 & 0.0053 & -0.1602 & 12.3058 \\
\hline CEE & & & & \\
\hline Hungary & 0.0003 & 0.0151 & -0.1206 & 6.4223 \\
Poland & 0.0002 & 0.0126 & -0.3677 & 3.6939 \\
Russia & 0.0004 & 0.0219 & -0.3942 & 8.5790 \\
South Africa & 0.0004 & 0.0120 & -0.1757 & 3.7160 \\
Turkey & 0.0003 & 0.0214 & -0.0615 & 7.7453 \\
Croatia & 0.0002 & 0.0129 & 0.0763 & 19.9496 \\
Estonia & 0.0004 & 0.0109 & 0.1260 & 9.4844 \\
Lithuania & 0.0004 & 0.0106 & -0.5439 & 28.4157 \\
Romania & 0.0006 & 0.0156 & -0.4017 & 9.3561 \\
Slovenia & -0.0001 & 0.0156 & -0.1132 & 323.5769 \\
\hline
\end{tabular}

The main findings from the preliminary analysis of the data shows the following. ${ }^{5}$ First, according to Q-statistics on raw data, serial correlation is evident in all return series. Second, all return series exhibit ARCH effects at the 0.05 level of significance. Third, unit root testing, by way of the Augmented Dickey-Fuller test and Kwiatkowski-Phillips-Schmidt-Shin test, indicate that all return series are stationary in levels or are integrated of order zero. Fourth, unconditional Pearson correlations during different periods indicate that stock market correlations are time varying. Fifth, the Sheppard and Engle (2001) and Tse (2000) tests for constant correlation are rejected in all cases.

Noting that almost all the return series are characterized by serial correlation, both AutoRegressive (AR) and Moving Average (MA) processes are tried to model serial correlation in the return series. Generally, for the first-step estimation of the DCC-GARCH approach, an ARMA $(1,1)$ GARCH $(1,1)$ process is found to be the best candidate based on both the Akaike Akaike Information Criterion and Schwarz Criterion.

\section{EMPIRICAL RESULTS}

The Engle's DCC method is used to investigate the possibility of time-changing correlations. ${ }^{6}$ None of the return series exhibit persistent volatility (that is, ARCH $(\alpha)+\mathrm{GARCH}(\beta)<1)$ and the estimated parameters, including $(\mathrm{ARCH}, \mathrm{GARCH})$, are generally significant.

We report the time-varying correlations over the full sample, for the preand post-GFC period and during the GFC (Sections A and B). We also look at the behaviour of DCCs between the CEE and other markets prior to, during, and following the ESDC (Section C).

\footnotetext{
5 For brevity, preliminary analyses are not reported. They are available on request.

6 Model estimation is carried out using the G@RCH 6 software. Laurent, S. 2009. Estimating and Forecasting ARCH Models Using G@Rch 6. Timberlake Consultants Ltd, UK.
} 


\section{A. The DCCs of Emerging Markets}

The DCCs for the whole period (referred to as the full sample from here on) are displayed in Tables 2-5, respectively, for Asia, CEE, Latin America, and MENA. The time-varying DCCs over the period 2002-2016 are presented as supplementary material in Figure S1. The DCCs for the GFC, and pre- and post-GFC sub-samples are available as part of supplementary materials in Tables S1-S4. The broad observations that can be made based on the results reported in Tables 2-5, S1-S4, and Figure S1 are as follows. First, previous studies that used data taken from years prior to 2012 note that the time-varying correlations were highest during the GFC and higher in the post-GFC period than the pre-GFC period. With the new data obtained in recent years (2013-2016), this remains true in most cases across the four regions, particularly the Asian and CEE regions. But we observe two additional features. One is that some markets in MENA and Latin America have systematically seen a weakening of their connections with Asian and CEE markets during troubled times (GFC) but an increase in connections after the GFC. ${ }^{7}$ And another is that there are many cases where the DCCs following the GFC were stronger than during or prior to the GFC. This suggests that, in recent years, the connection between emerging markets has increased.

Second, the time-varying correlations between Asian countries and the other emerging markets vary significantly, not just across time but also across DCC pairs ranging, on average, from $2 \%$ to $63 \%$ (Table 2). This suggests that Asian markets were more connected with the emerging/frontier markets in some regions than in others on an average day over the period 2002-2016. The same applies to the CEE markets, where the DCCs vary in the range of $-0.1 \%$ to $57 \%$ (Table 3). In the MENA region, for South Africa the DCCs range from $26 \%$ to $63 \%$, but for the rest of the MENA nations DCCs are in the range of $-1 \%$ to $23 \%$ (Table 4). The DCC connection between each of the Latin American nations and other emerging nations is the weakest, with DCCs falling in the range of $-6 \%$ to $6 \%$ (Table 5).

Third, the DCCs between South Africa and Malaysia averaged $63 \%$ for the period 2002-2016, making the two markets the most connected of all markets in the sample (Tables 2 and 4). The DCCs between Lithuania and Mexico were $-6 \%$, making these two the least connected markets in the sample (Tables 3 and 5).

\section{A.1 Asia}

We generally observed that, across the Asian region, there is a lack of significant DCCs between Asian and Latin American nations, and in some cases between Asian nations (such as Malaysia and Thailand) (see Table 2). Most reported

\footnotetext{
The MENA markets in Oman, Morocco, Tunisia, Jordon, and Lebanon saw a fall in average DCCs against Asia during the GFC (Table S1). With CEE nations, a fall in connection was noticed for Kenya, Oman, and Morocco (Table S2). The Latin American nations witnessing a weakening of connections with Asia were Chile, Colombia, and Mexico, and those with CEE were Colombia and Mexico (Table S1). CEE's connection with Sri Lanka also fell during the GFC (Table S2). The rest of the markets that showed time-varying correlations experienced an increase in DCCs during the GFC. Whether the GFC caused the fall in the DCCs is explored in Section B. For some Asian and CEE markets with Oman, Morocco, Colombia, Mexico, Pakistan, and Kuwait, we find that the GFC was strongly associated with a fall in the DCC.
} 
DCCs are significant at the 5 percent level or better. A few pairwise DCCs show weak to no significance. These are India's DCCs with Thailand, Lebanon and Mexico; Malaysia's with Mexico; Indonesia's with Tunisia, Lebanon, Mexico, and Columbia; Korea's with Lebanon; Sri Lanka with Greece, Kenya, Morocco, Hungary, and Lebanon.

The three most connected Asian markets are India, Indonesia, and Korea, although they have had a varying degree of connection with stock markets across Asia, CEE, MENA, and Latin America (Figure S1). For India, the DCCs vary significantly across the three regions: within Asia, the DCCs are in the range of 11-49\%; for CEE, the range was 20-37\%; and within MENA, it was 3-41\%.

Over time, the DCCs for India have behaved in a way that is generally consistent with the findings of previous studies. That is, the DCCs increased during the GFC and declined in the non-GFC period. However, we see that India's DCCs with markets in selected countries, such as, Thailand, Tunisia, Hungary, Poland, South Africa, Croatia, Romania, and Lebanon were higher in the post-GFC period (Table S1). This indicates increased interdependence between India and these emerging markets since the GFC, and therefore that diversification opportunities for Indian traders within these markets may have diminished.

For Indonesia, the DCC did not vary significantly across Asia (46-47\%). In the Latin American region, Indonesia was only integrated significantly with Mexico (around 2\%). However, within MENA, the DCCs for Indonesia varied in the range of $3-38 \%$. Similarly, for the CEE, Indonesia's DCCs was within the range of 16$31 \%$. The DCCs between Indonesia and MENA were higher during the post-GFC period compared to the GFC or pre-GFC period (Table S1). Robiyanto (2018) found similar results to us; using the DCC-GARCH models, the author found that the degree of integration had increased between Jakarta stock market and selected emerging/developed markets, except Australia, Philippines, and Tokyo, during the GFC to post-GFC period compared to the pre-GFC period.

Pakistan had DCC s with only one Asian country, India (11\%), only one CEE nation, Hungary (8\%), and a few MENA nations (6-12\%). The post-GFC DCCs for Pakistan were higher than the DCCs during the GFC or the pre-GFC period for all above-mentioned countries except India, which had higher DCCs in the GFC period. Surprisingly, Malaysia had no DCCs with other Asian markets, but had strong and time-varying ties with the CEE (24-57\%) and MENA (43-63\%) markets. The GFC period showed stronger DCCs for Malaysia than the pre- and post-GFC periods with all countries except South Africa, Croatia, and Romania. Similarly, Thailand had DCCs with CEE (16-34\%) and MENA (8-35\%), with evidence of increased interdependence with Kenya, South Africa, and Croatia in the post-GFC period.

Korea had DCCs with Thailand (42\%), the only Asian nation with whom its relations were time-varying, CEE (20-39\%), and MENA (3-43\%), with the GFC period producing higher DCCs than the pre- and post-GFC periods. 


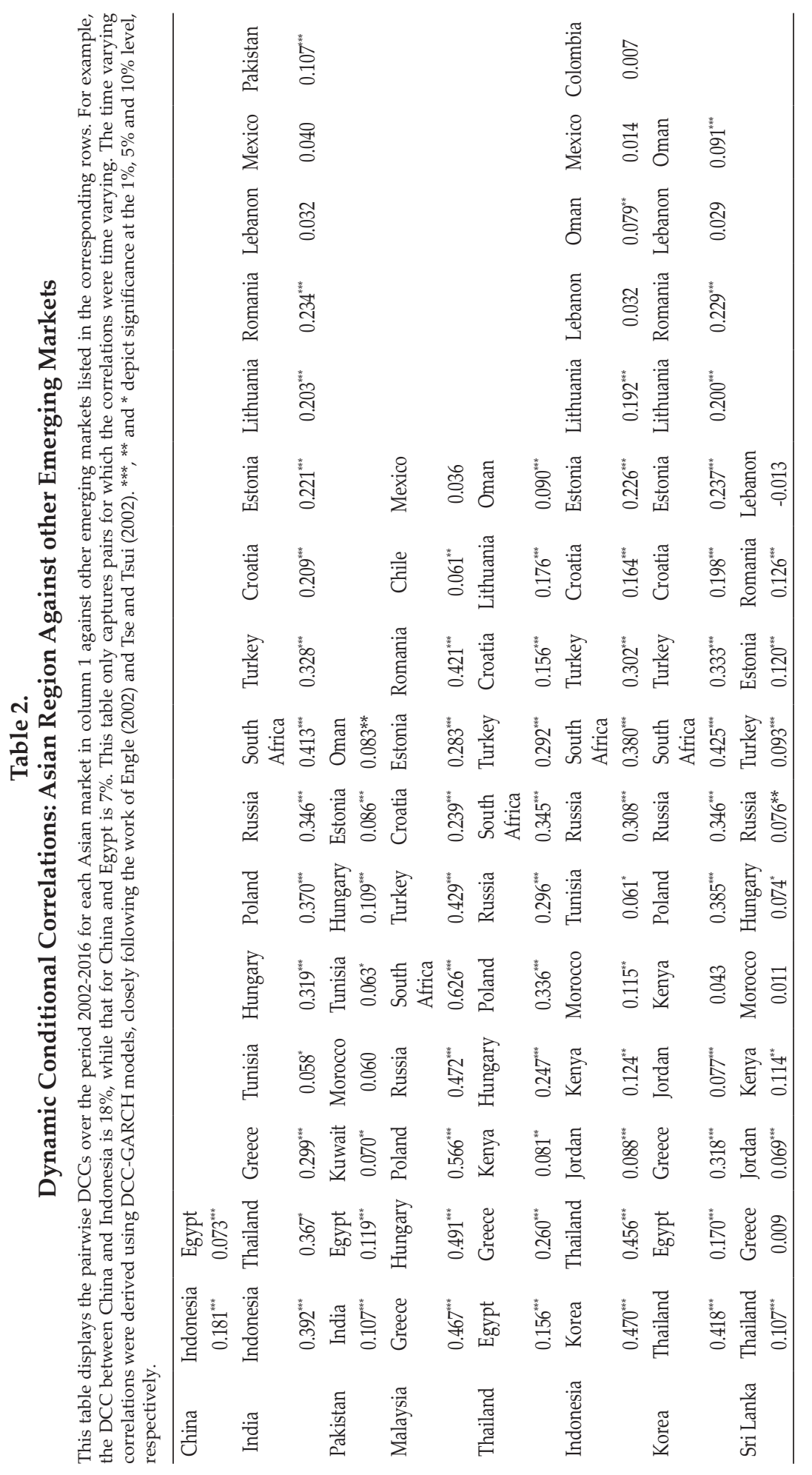


China's stock market was the least connected to other emerging markets in Asia in terms of DCC. China's conditional correlations are highest for Indonesia (18\%), followed by Egypt (7\%). In this regard, it seems that Asian national stock markets are still very disconnected with each other. Based on the DCCs calculated for this region, it appears that Asian traders, other than those from India and Indonesia, have looked outward to diversify their portfolio. This suggests that Asian traders have significant opportunities to diversify within their own region on a day-today basis if they are holding the stocks of their own country. For China (Korea), our study somewhat aligns (does not align) with Lee and Jeong (2014), who found a lack of stock market integration between the Northeast Asian markets and CEE markets over the period January 2000 to December 2012.

\section{A.2 CEE}

For the CEE nations, the DCCs, as displayed in Table 3, are with other CEE, several Asian, and a few MENA and Latin American nations. Most reported DCCs are highly significant. Reported DCCs, which are insignificant include: Greece with Sri Lanka; Hungary with Morocco; Lithuania with Lebanon, Kenya, and Morocco; Poland with Kenya and Mexico; Russia with Brazil and Mexico; Croatia with Jordon and Kenya; and Romania with Mexico and Morocco. Among the CEE nations, the post-GFC period saw the unfolding of the ESDC, and as a result significant capital flight (Table S3; Figure S1). This period coincided with a significant decline in the DCCs of CEE nations with other emerging markets. During this period, we notice that Hungary was one of the nations that was heavily involved in diversifying its risks by investing in other emerging regions. Overall, the average DCCs of the CEE region with Asia were in the range of $1-57 \%$; with $C E E$, in the range of $19-55 \%$; with MENA, in the range of 5-50\%; and with Latin America, in the range of $-6-1 \%$.

For Estonia, the DCCs with other CEE countries was in the range of 19-36\%; with Asia, in the range of 9-28\%; and with Oman, the only MENA nation, at $12 \%$ (Table 3). The GFC period showed stronger DCCs between Estonia and most nations than the pre- and post-GFC period (Table S2). However, with Romania, Oman, and Pakistan, Estonia's DCCs were stronger in the post-GFC period.

Greece's DCCs with Asia were in the range of 1-32\%; with the CEE, in the range of $21-42 \%$; and for MENA, in the range of $34-35 \%$. The post-GFC period saw lower DCCs for Greece, except its connections with Croatia. Hungary's timevarying correlations, on average, were in the range of $25-55 \%$ with other CEE nations, $7-49 \%$ with Asian countries, and 5-44\% with the MENA nations. The post-GFC period saw a fall in the DCC between Hungary and all other nations in the sample except Romania, India, Pakistan, Sri Lanka, Kenya, Morocco, and Tunisia. Hence, during the ESDC, Hungary was vigorously diversifying risks by forging stronger connections with Asian and MENA stocks. 


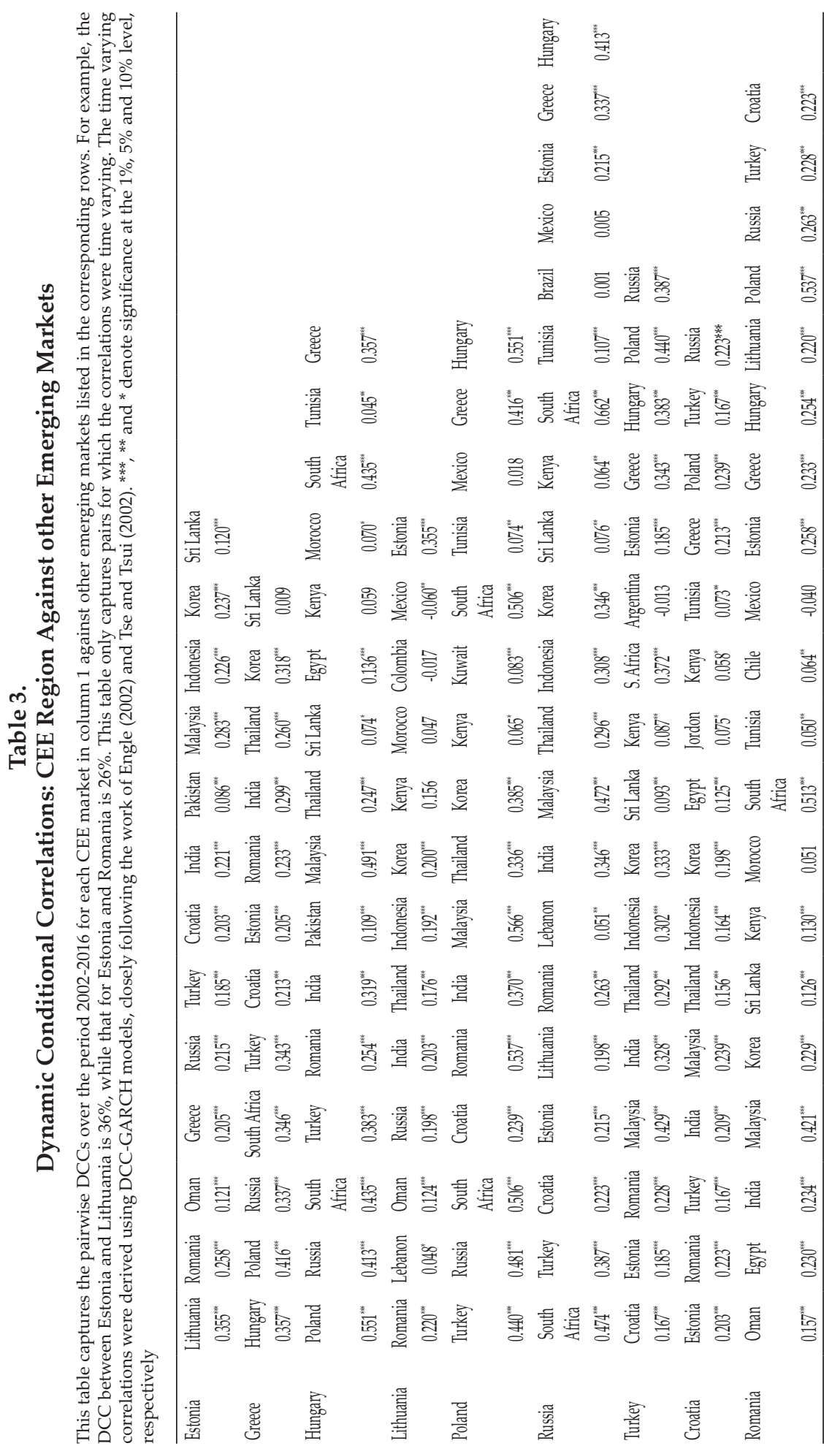


Lithuania, Russia, Turkey, and Poland were the only CEE nations connected with the Latin American nations, although these connections are negative or weak compared to other regions. Lithuania had negative DCCs with Mexico, which were $6 \%$, on average, over the review period, while Poland had positive DCCs with Mexico at an average of $2 \%$. Poland's DCCs with Asia were in the range of 33-57\%; with CEE, in the range of 24-55\%; and with MENA, in the range of 7-51\%.

For Russia, the DCCs with Mexico, on average, were 1\%; while with Brazil this figure was -negative 1\%. For CEE nations, Russia's DCCS were in the range of $21-41 \%$; with Asia, in the range of $8-47 \%$; and for MENA, in the range of $10-47 \%$ (Table 3). Compared to the GFC period, the post-GFC period saw a fall in Russia's DCCs with all markets except Romania, Lebanon, Sri Lanka, and Mexico (Table S2).

Turkey had DCCs with some CEE nations (17-44\%); Asia (9-33\%); MENA (8-37\%); and one country in Latin America, Argentina, at $-1 \%$. Turkey's DCCs following the GFC fell for all countries except Romania. Croatia's DCCs with CEE countries were in the range of 17-22\%; with Asia, 16-24\%; and with MENA, $6-13 \%$. The post-GFC period saw a rise in the DCCs from the GFC period for 9 out of the 15 nations: Romania, India, Malaysia, Thailand, Korea, Sri Lanka, Kenya, Greece, and Poland.

Some 20 nations had a dynamic connection with Romania, with the DCCs with other CEE nations falling in the range of 22-26\%; with Asia, in the range of $13-$ $25 \%$; and with MENA, in the range of $5-27 \%$ (Table 3). The post-GFC DCC were larger than those seen in the GFC period for all countries except Korea, Kenya, Tunisia, and Greece (Table S2).

\section{A.3 MENA}

For the MENA nations, we found DCCs with some emerging markets from Asia, CEE, and MENA, but not Latin America (Table 4; Figure S1). For this region, the DCCs with Asia varied significantly, ranging from $-1 \%$ to $63 \%$ - the higher DCCs are likely due to the strong ties that South Africa has with Asia. The DCCs of other MENA national markets with Asia were less than 10\%. With the CEE, MENA's DCCs were in the range of $5-51 \%$ and within MENA, $2-17 \%$.

Egypt's DCCs with other emerging markets were in the range of $7-23 \%$. Egypt was seen to strengthen its DCCs with some emerging markets after the GFC, which suggests slightly stronger connections with MENA countries, namely Oman, Kuwait, and Kenya, with Asian markets like China and Pakistan, and with CEE markets, namely Croatia and Estonia (Table S3).

Jordon's DCCs with emerging markets were in the range of $7-11 \%$, with an increase in all connections in the aftermath of the GFC, except its DCC with Oman. Kenya's DCCs with emerging markets were also very low, ranging between $2 \%$ and $13 \%$, yet Kenya's DCCs increased with all countries other than Turkey, Romania, and Korea during the GFC period. 


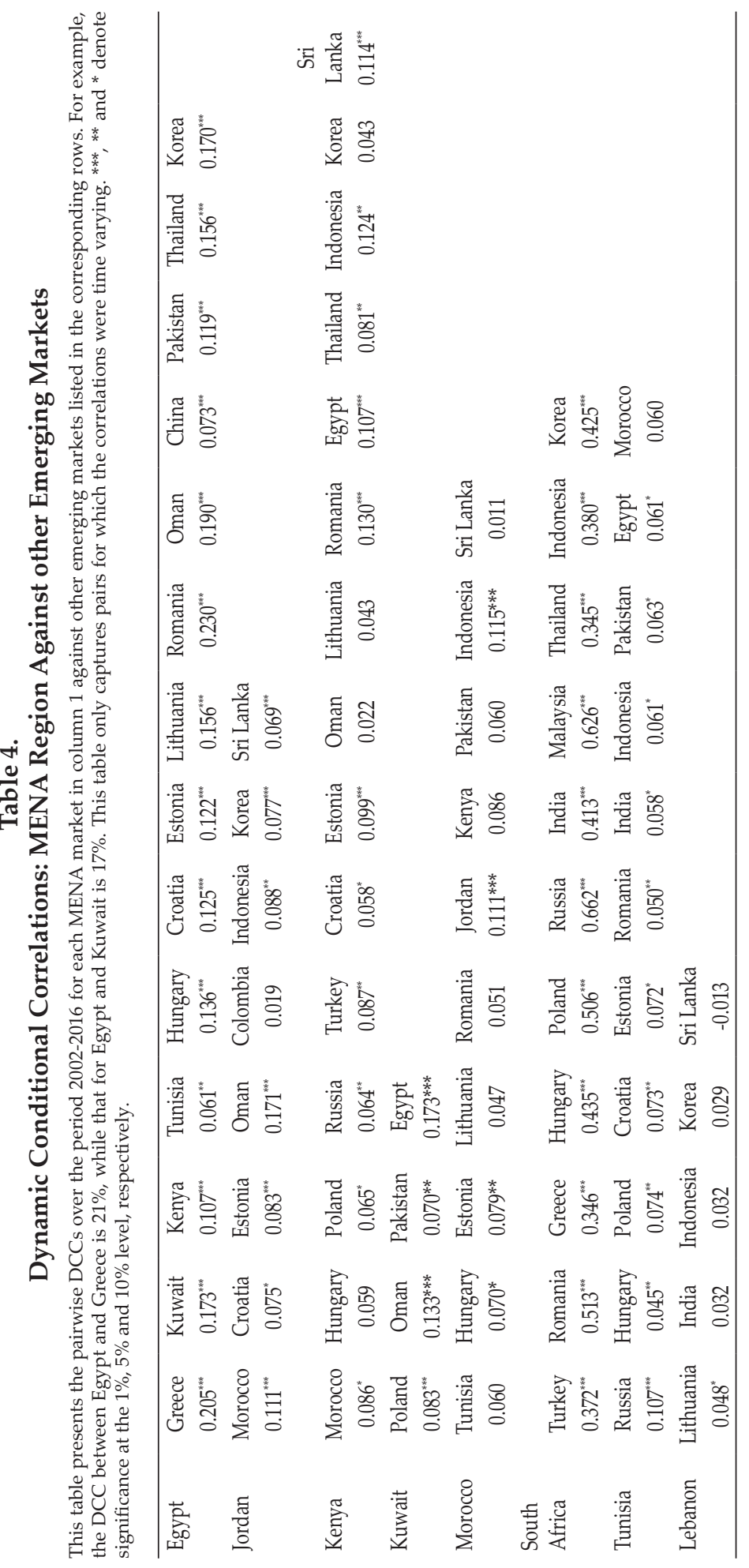


In terms of DCCs, Kuwait was the nation least connected with other emerging markets (only four connections). Its DCCs were in the $7-17 \%$ range, with all increasing following the GFC, except that with Oman. Lebanon was another MENA nation with minimal connections, having DCCs with only five emerging nations, which were in the range of $-1-3 \%$, the lowest range across the sample.

Morocco's DCCs ranged from $1 \%$ to $11 \%$ and has primarily increased its connections with emerging markets in the post-GFC period, except in the case of Tunisia, Estonia, and Sri Lanka. South Africa had the strongest ties with emerging markets, with DCCs ranging from $27 \%$ to $63 \%$. The post-GFC period saw an increase in South Africa's connections with Romania, Poland, India, Malaysia, and Thailand (Table S4).

Tunisia's ties with emerging markets in terms of DCCs were in the $5-11 \%$ range, increasing since the GFC in the case of Hungary, Poland, Estonia, India, Indonesia, and Pakistan.

\section{A.4. Latin America}

Like MENA, Latin America was a region displaying the weakest connections with other emerging markets (Figure S1). DCCs across the region ranged from $-2 \%$ to $6 \%$ only (Table 5). Coincidently, only half of the MENA countries carry DCCs with a high level of significance. Lebanon and Morocco, as reported above, show weak to no significance with most reported DCCs, while Kenya and Tunisia show limited cases of DCCs with high level of significance.

Mexico showed the most connections (with 10 markets) - the DCCs with these emerging markets were in the range of $-1-6 \%$. In the post-GFC period, Mexico's DCC s have increased for all nations, except for India and Romania.

Chile had six DCC-based connections, with average daily DCCs ranging from $-2 \%$ to $6 \%$. Its connections with all other markets suffered during the GFC, except that with Romania (which remained stable) and Argentina (which increased) (Table S4). The post-GFC period saw an increase in Chile's connections with Indonesia, Malaysia, Turkey, and Oman, no change in the DCC with Romania, and a weakening of the connection with Argentina.

Colombia had four connections based on the DCC model. Its DCCs ranged from $-2 \%$ to $2 \%$. All four connections strengthened in the post-GFC period. Brazil and Argentina showed the least interaction with emerging markets, with each having only three connections. For Argentina, the DCCs ranged from $-2 \%$ to $2 \%$; and for Brazil, they were in the range of $-1-2 \%$.

\section{B. Did the GFC Really Matter for the DCCs?}

We tested the significance of the GFC event, as well as the significance of the periods before and after the event, using the regression model: $D C C_{i j, t}=\alpha+\beta X_{t}+\varepsilon_{t^{\prime}}$ where $D C C_{i j}$ is the dynamic conditional correlation between two nations, $i$ and $j ; \varepsilon$ captures the unexplained portion of the DCCs; $\alpha, \beta$ are the parameters to be estimated; and $X$ is a binary variable that takes the value 1 for the GFC period (February 2007 - May 2008), the pre-GFC period (January 2002 - January 2007), 


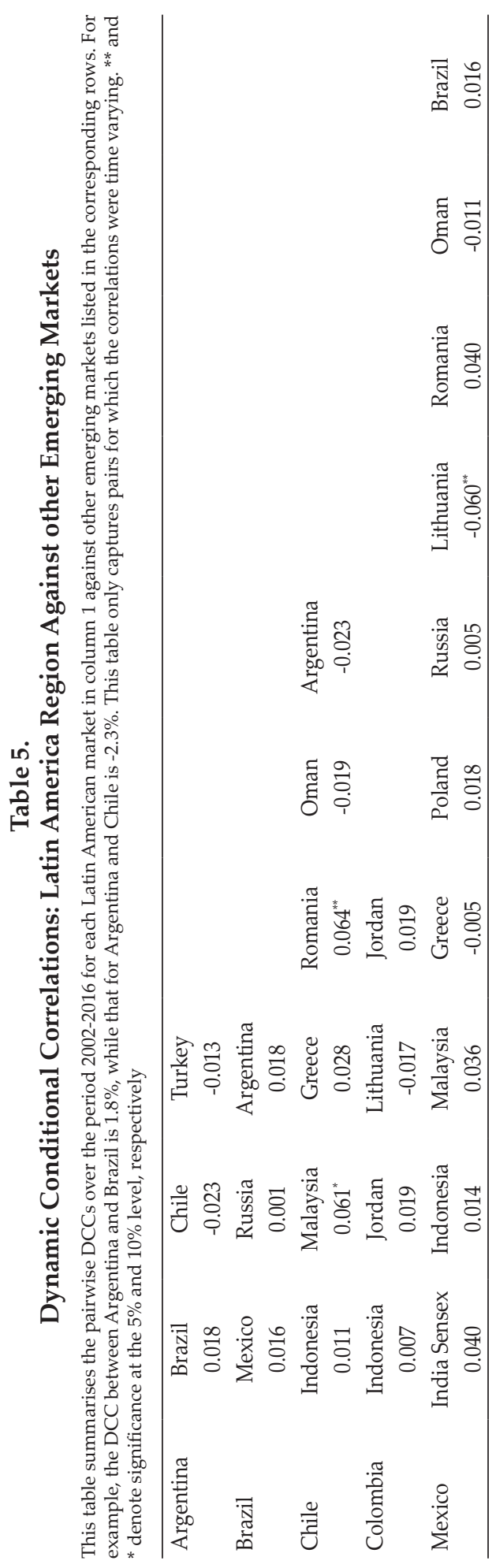


and the post-GFC period (June 2008 - November 2016), and zero otherwise. The main findings from these unreported results are summarised below. ${ }^{8}$

Prior to the GFC, on average, $80 \%$ of DCCs between the emerging and frontier markets were negative and significant, indicating that most DCCs in the period preceding the GFC were lower than those of any other period studied between January 2002 and November 2016.

During the GFC, on average, $82 \%$ of the DCCs between the emerging and frontier markets were positive and significant. This suggests that, for most of the pairs studied, the DCCs were higher in the GFC period than in the other periods.

In the post-GFC period, on average, $43 \%$ of the DCCs between the emerging and frontier markets were negative and significant. This implies that, in the postGFC period, $57 \%$ of pairs of emerging and frontier markets were more integrated than during the GFC period. This confirms our observations on the DCC averages presented in the previous sections.

\section{The ESDC and DCCs}

In the post-GFC period (June 2008 - 2016), we noticed significant movement in the DCCs. Instead of a reversal of the DCCs following the GFC, which earlier studies have consistently found, we noticed that, with the inclusion of more recent years, in several cases the emerging markets' DCCs continued to intensify. More recent studies report similar phenomena with developed and some emerging markets (see Rahim and Masih, 2016; and Najeeb et al., 2015). Indeed, the postGFC period coincides with the peaking of the ESDC, which probably explains the intensification. ${ }^{9}$

Only two studies have investigated the ESDC event. Harkmann (2014) examined the impact of the ESDC on stock market integration between Eurozone (Euro STOXX 50 Index) and selected CEE countries (Bulgaria, Czech Republic, Estonia, Hungary, Latvia, Lithuania, Poland, and Romania) using the DCCGARCH approach based on daily indices from 2002 to 2012. Harkmann (2014) identified three distinct time periods: 2002 to early 2006 with an average correlation of less than 0.35; following 2006, when the average correlation of the group displayed an upward trend; and 2008-2012, when the correlation reached a peak. Harkmann (2014) found that Bulgaria and Latvia had low correlations, while the Czech Republic, Hungary, and Poland demonstrated stronger correlations during the ESDC period. Overall, Harkmann's (2004) findings suggested that the ESDC increased the correlation between these countries.

Ahmad, Bhanumurthy, and Sehgal (2014) employed daily data for the years 1996-2012 to examine the integration of stock markets in the GIPSI countries (Greece, Ireland, Portugal, Spain, and Italy) with the US, seven Eurozone, and six non-Eurozone stock markets using the DCC-GARCH approach and comparing the ESDC with non-crisis period. The highest stock market integration was found

\footnotetext{
For brevity, these results are not reported but available on request.

9 The GFC covers the period February 2007 - May 2008; the peak of the ESDC and the upshot of this event played out over the period June 2008 - December 2012; and, hence, given that our sample ends in November 2016, the post-ESDC period covered January 2013 to November 2016.
} 
between France and GIPSI countries in Eurozone markets, followed by Belgium, Austria, Germany, and the Netherlands, with Slovakia exhibiting the lowest correlation with the GIPSI countries. In the case of non-Eurozone countries, the UK had the highest stock market integration with the GIPSI countries, followed by Sweden, Denmark, Norway, Hungary, and the Czech Republic. Ahmad, Bhanumurthy, and Sehgal (2014) also identified significant variation in the correlations during the Eurozone crisis period, with increasing correlation seen during the ESDC. Their results further suggested that the post-subprime crisis in the US had a strong impact on the European stock market, indicating that the US stock market influences the degree of correlation in the European markets.

In line with these studies, we investigated whether the increase in DCCs we saw in the post-GFC period coincided with the ESDC. Our contribution comes from using a comprehensive list of emerging markets to assess their interaction with the CEE markets. We calculated the DCCs for both the ESDC and post-ESDC periods. These results are presented in Tables 6 and S5. Table 6 displays the average DCCs of CEE nations with other CEE nations and other regions, while Table S5 reports the average DCCs between emerging markets from Asia, Latin America, and MENA during and following the ESDC.

Some interesting results are revealed. Greece, one of the European nations impacted significantly the ESDC, experienced significant capital flight because of the ESDC and this is evident in the decline in Greece's DCCs with almost all the nations with which it had time-varying correlations. Despite the two bailouts ${ }^{10}$, the average DCCs of Greece with all emerging markets continued to fall in the period following the peak of the ESDC (see results relating to the ESDC period, Table 6, column 2 and the last four rows). Incidentally, the DCCs between all CEE nations and Greece fell as well (see average DCCs reported for the ESDC period, Table 6, column 2).

As is widely known, wary traders/investors, whether foreign or domestic, tend to reduce their associations with troubled regions, albeit temporarily. Despite the exodus from Greece, we notice a general increase in the DCCs within the CEE region. However, our results identified some disengagement within the CEE region during the ESDC. This was seen in two ways. First, the association between most CEE (except Greece) and emerging/frontier markets increased during the ESDC period (Table 6). This implies that traders in the troubled CEE region began to look at investment opportunities outside the region. We then noticed a reversal of this trend in the post-ESDC period, so when policymakers began to address the problems, CEE based traders regained faith and began to return to their region for investment diversification. Second, during the ESDC the average size of the DCCs between emerging and frontier markets in regions excluding CEE also increased. These average DCCs are reported in Table S5. If traders were wary about the CEE region during this time, one would expect an increase in the associations between emerging or frontier markets other than the CEE markets. And, in most cases,

\footnotetext{
${ }^{10}$ Since the creation of the European Union in 1992 and the subsequent launch of the euro, Greece is the first country to resort to a financial assistance program in May 2010. A year later, a worsened recession along with the poor performance of the Greek government in achieving the conditions of the agreed bailout, forced a second bailout in July 2011 (Ardagna and Caselli, 2014).
} 


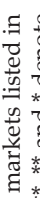

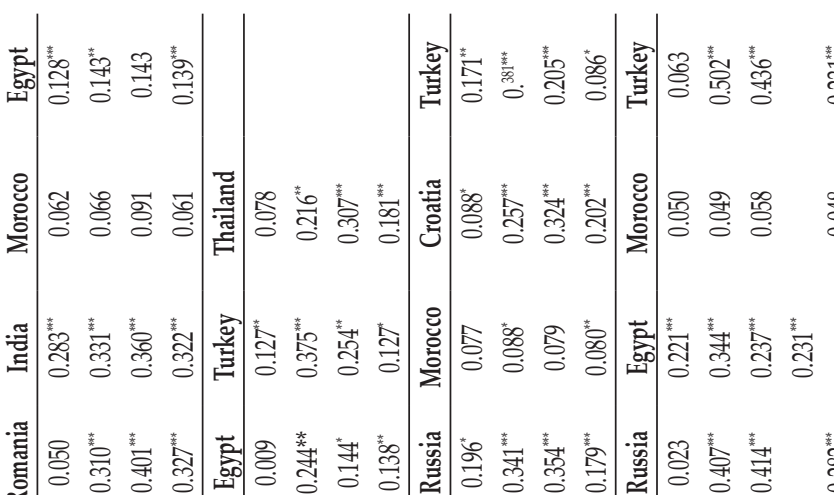

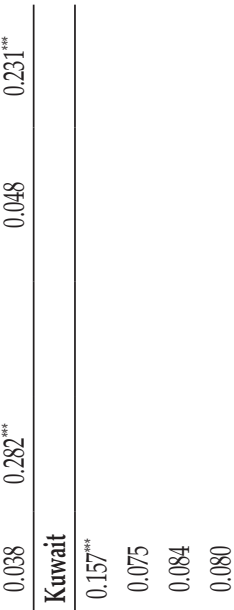

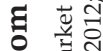

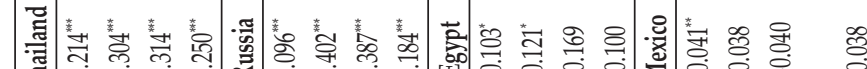

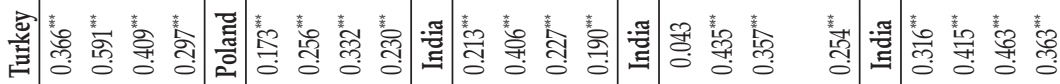

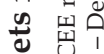

츄

o. 总吉

. บิنั

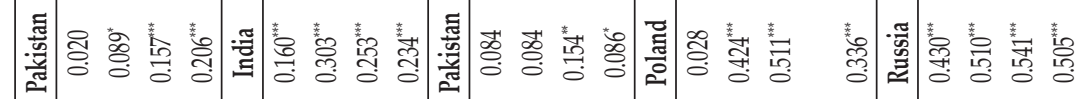

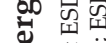

四 范客

它

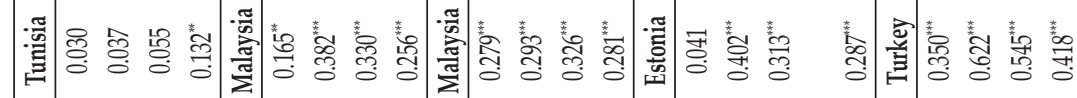

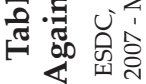

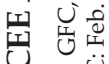

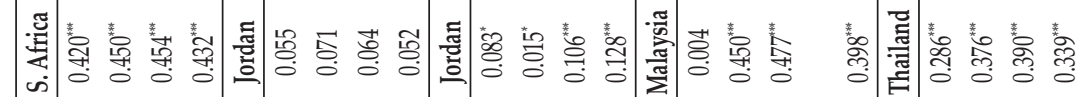

ن․

की 离容

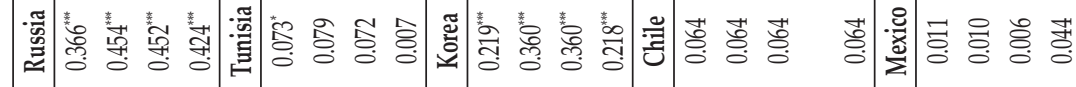

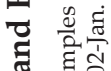

ป

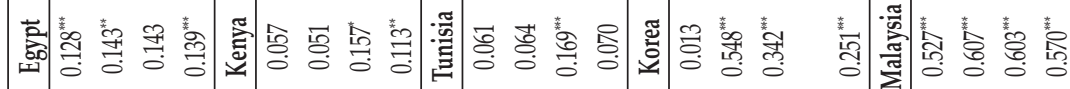

U

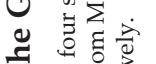

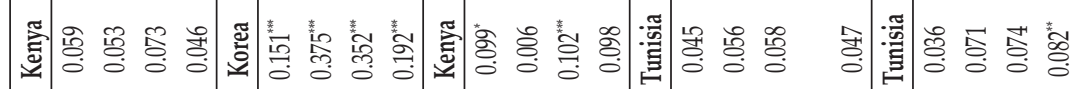

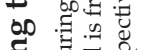

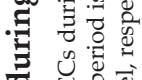

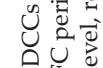

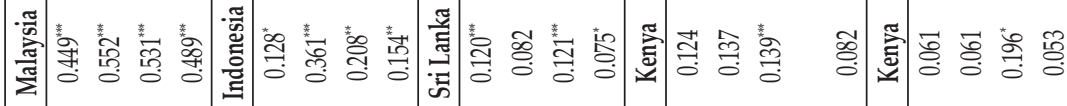

U

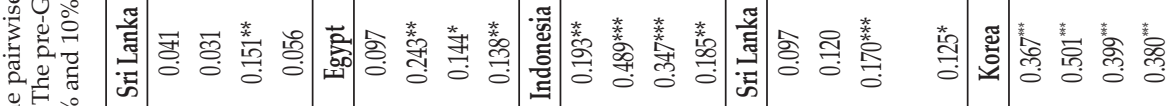

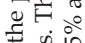

\%

(द)

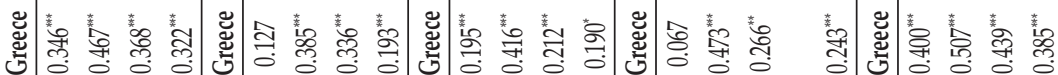

क्ञ है

要

色焉

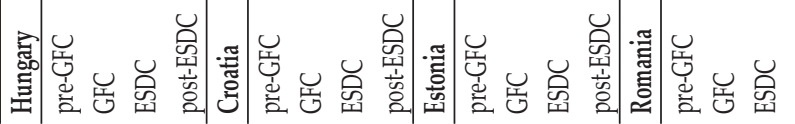

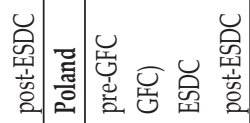




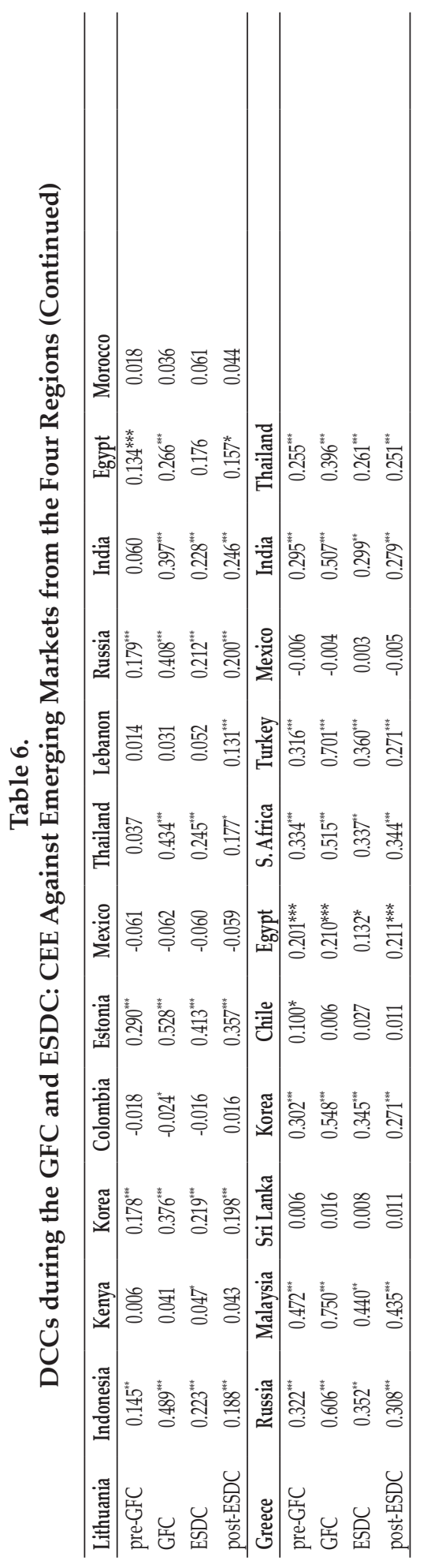


we did observe an average increase in DCCs between markets in regions, other than CEE during the ESDC period. This confirms that traders were indeed wary of investing in the troubled CEE region at that time. However, in the post-ESDC period, our DCC averages point to a reversal in all cases, indicating that traders chose to return to the CEE region as events took a positive turn.

Confirming the above, in 53 out of 85 cases, we found that the DCCs between emerging markets rose during the ESDC, only to fall following this crisis, in the 2013-2016 period (Table S5). This upward movement in DCCs suggests that the ESDC may have led to stronger associations between not only the CEE and other emerging markets but also between emerging markets excluding the CEE markets. As the situation improved, the upward trend seen in the DCCs of CEE (excluding Greece) and other emerging markets in the ESDC period thus underwent a reversal in the years 2013-2016.

To this point, these shifts in DCCs are explained based on the DCCs over the ESDC and post-ESDC periods. However, we also conducted tests to identify whether the ESDC, pre-ESDC and post-ESDC periods influenced the DCCs with CEE markets. The following regression model was thus estimated: $D C C_{C E E, j, t}=\alpha+\beta X_{t}+\varepsilon_{t^{\prime}}$ where $D C C_{i j}$ is the dynamic conditional correlation between two nations - a CEE nation and an emerging/frontier market from Asia, Latin America or MENA $(j) ; \varepsilon$ captures the unexplained portion of the DCCs; and $\alpha, \beta$ are the parameters to be estimated. Here, $X$ is a binary variable that takes the value 1 for the ESDC period (June 2008 - December 2012), the pre-ESDC period (March 2002 -May 2008) and the post-ESDC period (January 2013 - November 2016), and zero otherwise. The condition $\beta \neq 0$ confirms the significance of the ESDC event. The size of $\beta$ indicates whether the DCCs were higher or lower in the periods relating to the ESDC event.

The key findings from these unreported results are as follows. ${ }^{11}$ For all except 14 pair-wise relationships, the DCCs were lower in the pre-ESDC period than in any other period. The ESDC period, on the other hand, saw higher DCCs between most CEE markets and Asian, Latin America or MENA markets than any other year. However, the DCCs were not higher in the case of Greece and some Asian (India, Japan, and Sri Lanka) and Latin America (Chile) markets. Apart from Greece, only Poland and Russia were found to have lower DCCs with Mexico in the ESDC period. This suggests that, during the ESDC period, the DCCs increased between CEE markets, and between most CEE markets and other emerging markets. The post-ESDC period saw a further rebalancing of the portfolios, with a decrease in DCCs, as evidenced by the DCC averages (as seen in Table 6).

\section{CONCLUSION}

This study sought to determine whether a trader, who has a stake in an MSCIbased stock market index in his/her home country - in Asia, CEE, Latin America, or MENA - has short-term diversification opportunities in any of these four emerging regions. Some of the common themes to emerge from this research in relation to each region are as follows. For Asia, while there are some well-connected Asian markets (such as India and Indonesia) with reduced opportunities to diversify

${ }^{11}$ For brevity, these results are not reported, but available on request. 
in recent years, several other Asian nations show no or a low level of integration with other emerging/frontier markets and could benefit the trader significantly from diversifying his/her risks in other emerging/frontier markets within these four regions. For CEE nations, there are more opportunities to diversify outside their markets than within them. Greece, on the one hand, showed clear signs of significant capital flight resulting from the ESDC crisis, with all its DCCs declining during the ESDC period. On the other hand, the integration of emerging markets with CEE markets increased during this period, which suggests that markets outside CEE became more lucrative for portfolio diversification. The DCCs between the CEE markets, except for Greece, rose in the ESDC period, which is a sign of contagion. In the case of MENA markets, there were no connections with Latin American markets and only weak connections with the markets in the other two regions. However, South Africa's stock market was an exception-it was found to be strongly integrated with Asian markets. The Latin American nations were found to have significant short-term connections with the MENA nations but very low connections with other markets both within Latin America and in CEE nations, making emerging and frontier markets lucrative for short-term diversification.

In all, it appears that, while emerging and frontier markets outside each region become lucrative in times of trouble, of all four regions, Asian markets were found to be most actively used to diversify risks. In terms of diversification opportunities, traders with home-biased portfolio in the Latin American region have the most opportunities to diversify their portfolio in the emerging/frontier markets in their region and other two regions. This is followed by traders in MENA, CEE, and finally traders in Asia, who have emerging and frontier markets at their disposal to diversify risks. This is for those traders living in one of the four regions and have a home biased investment.

By examining DCCs in relation to the GFC, the broad observation was that our results are consistent with past studies, which reveal an increase in correlations during the GFC followed by a fall in its aftermath across all four regions, but particularly Asia and CEE. However, in many cases, we found that the DCCs were stronger following the GFC than during or prior to the GFC. We took this to mean that, in recent years, overall, the connection between emerging markets has increased.

When we considered CEE's DCCs before, during, and after the ESDC, we found that the DCCs between Greece and other emerging/frontier markets generally fell, but that other nations of CEE increased their DCCs with the emerging/frontier markets of the other three regions. A reversal of these DCCs was noticed after the ESDC. This suggests that this crisis forced CEE nations to diversify their portfolios outside their region during this period. 


\section{REFERENCES}

Agmon, T., \& Lessard, D. R. (1977). Investor Recognition of Corporate International Diversification. The Journal of Finance, 32,1049-1055.

Ahmad, W., Bhanumurthy, N., \& Sehgal, S. (2014). The Eurozone Crisis and its Contagion Effects on the European Stock Markets. Studies in Economics and Finance (Charlotte, N.C.), 31, 325-352.

Ardagna, S., \& Caselli, F. (2014). The Political Economy of the Greek Debt Crisis: A Tale of Two Bailouts American Economic Journal: Macroeconomics, 6, 291- 323

Arouri, M. E. H, \& Nguyen, D. K. (2009). Time-varying Characteristics of Crossmarket Linkages with Empirical Application to Gulf Stock Markets. Managerial Finance, 36, 57-70

Arouri, M. E. H. \& Nguyen, D. K. (2010) Time-varying Characteristics of Crossmarket Linkages with Empirical Application to Gulf Stock Markets, Managerial Finance, 36, 57-90.

Baltzer, M., Stolper, O., \& Walter, A. (2013). Is Local Bias a Cross-border Phenomenon? Evidence from Individual Investor's International Asset Allocation. Journal of Banking and Finance, 37, 2823-2835.

Bollerslev. T., \& Wooldridge, J. M. (1992) Quasi-maximum Likelihood Estimation and Inference in Dynamic Models with Time-varying Covariances. Econometric Reviews, 11, 143-172.

Bouri, E. I. (2014). Israeli-Hezbollah War and Global Financial Crisis in the Middle East and North African Equity Markets. Journal of Economic Integration, 29, 1-19.

Budd, B. (2018). The Transmission of International Stock Market Volatilities. Journal of Economics and Finance, 42, 155-173.

Chittedi, K. R. (2015). Financial Crisis and Contagion Effects to Indian Stock Market:'DCC-GARCH'analysis. Global Business Review, 16, 50-60.

Cooper, I. A., \& Kaplanis, E. (1994). Home bias in equity portfolios, inflation hedging, and International Capital Market Equilibrium. Review of Financial Studies, 7, 45-60.

Coval, J. D., \& Moskowitz, T. J. (2001). The Geography of Investment: Informed Trading and Asset Prices Author(s). The Journal of Political Economy, 109, 811841.

Dajčman, S., \& Festić, M. (2012). Interdependence between the Slovenian and European Stock Markets - A DCC-Garch Analysis. Economic ResearchEkonomska Istraživanja, 25, 379-395.

de Dreu, J., \& Bikker, J. A. (2012). Investor Sophistication and Risk Taking. Journal of Banking and Finance, 2145-2156.

Engel, R. F. (2002). Dynamic Condition Correlation - A Simple Case of Multivariate GARCH Models. Journal of Business and Economic Statistics, 20, 339-350.

Errunza, V. R. (1977). Gains from Portfolio Diversification into Less Developed Countries' Securities. Journal of International Business Studies, 8, 83-100.

Errunza, V. R. (1983). Emerging Markets: A New Opportunity for Improving Global Portfolio Performance. Financial Analysts Journal, 39, 51-58.

French, K., \& Poterba, J. (1991). Investor Diversification and International Equity Markets. American Economic Review, 81, 222-26.

Grinblatt, M., \& Keloharju, M. (2002). How Distance, Language, and Culture Influence Stockholdings and Trades. The Journal of Finance, 56, 1053-1073. 
Grubel, H. G. (1968). Internationally Diversified Portfolios: Welfare Gains and Capital Flows. The American Economic Review, 58, 1299-1314.

Grubel, H. G., \& Fadner, K. (1971). The Interdependence of International Equity Markets. The Journal of Finance, 26, 89-94.

Harkmann, K. (2014). Stock Market Contagion from Western Europe to Central and Eastern Europe During the Crisis Years 2008-2012. Eastern European Economics, 52, 55-65.

Hung, N. T. (2019). Equity Market Integration of China and Southeast Asian Countries: Further Evidence from MGARCH-ADCC and Wavelet Coherence Analysis. Quantitative Finance and Economics, 3, 201-220.

Hwang, J. (2014). Spillover Effects of the 2008 Financial Crisis in Latin America Stock Markets. International Advances in Economic Research, 20, 311-324.

Ivković, Z., \& Weisbenner, S. (2005). Local Does as Local is: Information Content of the Geography of Individual Investors' Common Stock Investment. The Journal of Finance, 60, 267-306.

Joyo, A. S., \& Lefen, L. (2019). Stock Market Integration of Pakistan with its Trading Partners: A Multivariate DCC-GARCH Model Approach. Sustainability, 11, 303-325.

Kang, J. K., \& Stulz, R.M. (1997). Why is there a Home Bias? An Analysis of Foreign Portfolio Equity Ownership in Japan. Journal of Financial Economics, 46, 3-28.

Lahrech, A., \& Sylwester, K. (2011). U.S. and Latin American Stock Market Linkages. Journal of International Money and Finance, 30, 1341-1357.

Lean, H. H., \& Teng, K. T. (2013). Integration of World Leaders and Emerging Powers into the Malaysian Stock Market: A DCC-MGARCH Approach. Economic Modelling, 32, 333-342.

Lee, G., \& Jeong, J. (2014). Global Financial Crisis and Stock Market Integration between Northeast Asia and Europe. Review of European Studies, 6, 61-75.

Lessard, D. R. (1973). International Portfolio Diversification: A Multivariate Analysis for a Group of Latin American Countries. The Journal of Finance, 28, 619-633.

Maghyereh, A. I., Awartani, B., \& Hilu, K. A. K. A. (2015). Dynamic Transmissions between the U.S. and Equity Markets in the MENA Countries: New Evidence from Pre- and Post-Global Financial Crisis. Quarterly Review of Economics and Finance, 56, 123-138.

Makridakis, S. G., \& Wheelwright, S. C. (1974). An Analysis of the interrelationships among the Major World Stock Exchanges. Journal of Business Finance and Accounting, 1, 195-215.

Maldonado, R., \& Saunders, A. (1981). International Portfolio Diversification and the Inter-Temporal Stability of International Stock Market Relationships, 195778. Financial Management, 54-63.

Markowitz, H. (1952). Portfolio Selection. The Journal of Finance, 7, 77-91.

Muharam, H., Mawardi, W., Arfinto, E. D., \& Najmudin, N. (2019). Volatility Spillovers under Difference in the Degree of Market Integration: Evidence from the Selected Asian and Eastern European Stock Markets. Journal of International Studies (Kyiv), 12, 134-150.

Najeeb, S. F., Bacha, O., \& Masih, M. (2015). Does Heterogeneity in Investment Horizons Affect Portfolio Diversification? Some Insights using M-GARCH- 
DCC and Wavelet Correlation Analysis. Emerging Markets Finance and Trade, 51, 188-208.

Narayan, S., Le, T-H., \& Srianathakumar, S. (2018). The Influence Of Terrorism Risk On Stock Market Integration: Evidence from Eight OECD Countries, International Review of Financial Analysis. 58, 247-259.

Narayan, S., Sriananthakumar, S., \& Islam. S. (2014). Stock Market Integration of Emerging Asian Economies: Patterns and Causes. Economic Modelling, 39, 1931.

Panda, A., \& Nanda, S. (2018). Time-varying Synchronisation and Dynamic Conditional Correlation among the Stock Market Returns of leading South American Economies. International Journal of Managerial Finance, 14, 245-262.

Panton, D. B., Lessig, V. P., \& Joy, O. M. (1976). Co-movement of International Equity Markets: A Taxonomic Approach. Journal of Financial and Quantitative Analysis, 11, 415-432.

Philippatos, G. C., Christofi, A., \& Christofi, P. (1983). The Inter-temporal Stability of International Stock Market Relationships: Another View. Financial Management, 63-69.

Pietrzak, M. B., Faldzinski, M., Balcerzak, A. P., Meluzín, T., \& Zinecker, M. (2017). Short Term Shocks and Long-term Relationships of Interdependencies among Central European Capital Markets. Economics and Sociology, 10, 61-77. http:// dx.doi.org/10

Qian, P. Y., \& Diaz, J. F. (2017). Volatility Integration of Global Stock Markets with the Malaysian Stock Market: A Multivariate GARCH Approach. Malaysian Journal of Economic Studies, 54, 83-117.

Rahim, A. M., \& Masih, M. (2016). Portfolio Diversification Benefits of Islamic Investors with their Major Trading Partners: Evidence from Malaysia based on MGARCH-DCC and Wavelet Approaches. Economic Modelling, 54, 425-438.

Ripley, D. M. (1973). Systematic Elements in the Linkage of National Stock Market Indices. The Review of Economics and Statistics, 356-361.

Robiyanto, R. (2018). Indonesian Stock Market's Dynamic Integration with Asian Stock Markets and World Stock Markets. Jurnal Pengurusan (UKM Journal of Management), 52.

Serrat, A. (1997), A Dynamic Equilibrium Model of International Risk-sharing Puzzles. Econometrica, 69, 1467-1489.

Seth, N., \& Panda, L. (2020). Time-varying Correlation between Indian Equity Market and Selected Asian and US Stock Markets. Global Business Review, 21, 1354-1375.

Šikić, L., \& Šagovac, M. (2017). An International Integration History of the Zagreb Stock Exchange. Public Sector Economics, 41, 227-257.

Solnik, B. H. (1974). An Equilibrium Model of the International Capital Market. Journal of Economic Theory, 8, 500-524.

Sriananthakumar, S., \& Narayan, S. (2015). Are Prolonged Conflict and Tension Deterrents for Stock Market Integration? The Case of Sri Lanka. International Review of Economics and Finance, 39, 504.

Stulz, R. (1981). On the Effect of Barriers to International Investment. Journal of Finance, 36, 923-934. 
Tesar, L. L., \& Werner, I.M. (1995). Home Bias and High Turnover. Journal of International Money and Finance, 14, 467-492.

Tse, Y. K. (2000) A Test for Constant Correlations in a Multivariate GARCH Model, Journal of Econometrics, 98, 107-127.

Wang, P., \& Moore, T. (2008). Stock Market Integration for the Transition Economies: Time-varying Conditional Correlation Approach. Manchester School, 76, 116-133. 